\title{
De la persistencia al olvido. La impronta constitucional gaditana en el Perú del siglo XIX
}

\author{
Víctor Peralta Ruiz \\ victor.peralta@cchs.csic.es \\ Consejo Superior de Investigaciones Científicas (CSIC) - España
}

\section{RESUMEN:}

El artículo propone como hipótesis la persistencia de los principios doctrinarios (liberales y conservadores) de la constitución de Cádiz en la codificación legislativa peruana del siglo XIX. Esta propuesta se probará a través de la vigencia de tres de los preceptos más significativos de la carta política doceañista: el voto de los analfabetos indígenas; la elección indirecta de los ayuntamientos provinciales y la protección estatal de la religión católica. A lo largo de este texto se hace un recorrido por las constituciones promulgadas entre 1823 y 1860, así como a la literatura política de la época, para comprobar el accidentado proceso de vigencia y de supresiones definitivas de estos tres preceptos.

Palabras Clave: Constitución de 1812; Perú siglo XIX; Voto Indígena; Ayuntamientos; Religión Católica.

\section{From Persistence to Oblivion. The imprint of the Constitution of Cadiz in XIXth- Century Peru}

\begin{abstract}
:
It is proposed that doctrinal principles (liberal and conservative) of the Cadiz Constitution of 1812 are present in the Peruvian legislative codification of XIXth century. This proposition is tested through the validity of three of the most significant precepts of that Constitution: the vote of the illiterate Indians, the indirect election of the provincial town councils and the legal protection of the Catholic religion by the State. Therefore, It is analyzed the Peruvian constitution between 1823 and 1860, as well as the political literature of that time.
\end{abstract}

Keywords: Spanish Constitution of 1812; XIXth century Peru; Indian Vote; Town Councils; Catholic Religion 


\section{Introducción}

Los especialistas conceden escaso protagonismo a la carta política de 1812 en la trayectoria constitucional republicana del Perú a diferencia de otras realidades hispanoamericanas (Landavazo y Sánchez Andrés, 2014) (Serna de la Garza, 2017) (Gamas Torruco, Juárez y Gutiérrez Hernández, 2014). Esta perspectiva está cambiando gracias a los recientes avances historiográficos dedicados al impacto del liberalismo hispánico (Peralta Ruiz, 2008) (Chiaramonti, 2005) (Hampe Martínez, 2015). El establecimiento de las Cortes de Cádiz en 1810 representó para el Perú el inicio de su recorrido hacia la plena adopción de la forma representativa de gobierno. El primer constitucionalismo hispánico transcurrió brevemente entre 1812 y 1814 . A pesar de reconocerse como un convicto ilustrado absolutista el virrey José Fernando de Abascal, que gobernaba el virreinato desde 1806, acató todas las disposiciones liberales que emanaron del máximo poder legislativo hispano. Entre estas cabe destacar la supresión del tributo indígena, la aplicación de la libertad de imprenta, la juramentación de la constitución de 1812, la celebración de elecciones para formar ayuntamientos constitucionales y diputaciones provinciales y la supresión de la Inquisición. Pero el virrey, hábilmente, encontró en los reglamentos y en los vacíos jurídicos de la legislación gaditana los recursos para contener eso que llegó a denominar como una «hemorragia liberal». La censura y cierre de los periódicos afines al doctrinarismo liberal, el destierro bajo partida de registro de los editores políticamente más incómodos, el restablecimiento de una contribución voluntaria sobre los indígenas $\mathrm{y}$, por último, la ofensiva discursiva contra los ayuntamientos constitucionales más díscolos, como lo fueron los que se establecieron en las capitales de Lima y Cusco, resumen el empeño de la máxima autoridad política de acatar pero incumplir lo mejor posible lo dispuesto por las Cortes. En este sabotaje político Abascal no solo contó con el apoyo de las autoridades peninsulares (oidores e intendentes), los militares y los grandes comerciantes, sino que también obtuvo el silencio cómplice de una parte significativa de la nobleza criolla peruana. El restablecimiento del régimen absolutista de Fernando VII en 1814 supuso la abrupta interrupción del liberalismo gaditano en todo el mundo hispánico que siguió bajo su dominación. En el Perú, Abascal publicó en noviembre de 1814 el bando con el que se puso fin al experimento liberal que él ya se había encargado de empequeñecer.

El segundo constitucionalismo gaditano en el Perú se corresponde con los años de vigencia del Trienio Liberal en España (1820-1823). El virrey Joaquín de la Pezuela la restableció mediante juramentación pública en agosto de 1820 , pocos días antes de que se produjera el desembarco en la bahía de Pisco de la expedición libertadora procedente de Chile y capitaneada por el general José de San Martín. Debido al imparable avance de las tropas patriotas por el norte y centro del virreinato, el segundo liberalismo hispánico en el Perú tuvo un impacto geográfico limitado y temporalmente breve en comparación con lo ocurrido en tiempos de Abascal. Pezuela apenas pudo restablecer algunos ayuntamientos constitucionales y la diputación provincial de Lima así como suprimir ya de modo definitivo la Inquisición (Peralta Ruiz, 2005) (Alvarado Luna, 2014). El descontento con este virrey expresado por el alto mando del ejército realista desembocó en el golpe de estado de Aznapuquio de enero de 1821 que dispuso su destitución y reemplazo por el brigadier José de la Serna. A este virrey de facto le correspondió aplicar el decreto de libertad de imprenta que llegó tardíamente de Madrid. El cerco patriota sobre Lima obligó al virrey y sus tropas a abandonar Lima a principios de julio de 1821. La Serna estableció su gobierno virreinal en la ciudad del Cusco y desde allí ejerció un dominio territorial y político sobre las provincias del sur andino peruano y del Alto Perú. La constitución de 1812 se aplicó limitadamente en estos espacios geográficos. Por ejemplo hoy se sabe que se celebraron elecciones para ayuntamientos constitucionales y para las diputaciones provinciales establecidas en Cusco, Ayacucho y Arequipa. Por el estado permanente de guerra el virrey La Serna no permitió la libertad de imprenta. La 
abolición de la constitución por parte de esta autoridad se produjo en mayo de 1824 una vez que, oficialmente, se conoció en el Cusco la abolición en España de la constitución de 1812 y el retorno al absolutismo de Fernando VII (Sala i Vila, 2011 y 2016). La derrota realista en la batalla de Ayacucho el 8 de diciembre de 1824 produjo la capitulación del virrey La Serna y jurídicamente significó para el sur andino el fin de una dominación normada por los preceptos absolutistas.

El breve resumen que se ha hecho en los párrafos anteriores sobre la trayectoria de la constitución gaditana en el virreinato del Perú sirve de preámbulo a este artículo en el que se tratará, fundamentalmente, de la persistencia en el siglo XIX peruano de algunos principios legales sancionados por primera vez por la constitución de 1812. La legislación del siglo XIX, en la que destacan las seis constituciones sancionadas entre 1823 y 1860 (García Belaunde, 1992) (Rubio Correa, 2003), a pesar de su indiscutible inspiración en las legislaciones republicanas francesa y estadounidense también mantuvo ciertos principios heredados de la carta gaditana. El artículo se propone desarrollar hasta qué punto se mantuvieron o se modificaron preceptos originados en la gran asamblea legislativa gaditana de 1810 a 1812 como la concesión de la ciudadanía a los indígenas analfabetos, la persistencia de los ayuntamientos elegidos por votación popular indirecta y la protección estatal exclusiva y excluyente de la religión católica. Se argumentará que entre los legisladores del siglo XIX peruano se respetó la herencia constitucional gaditana como una alternativa necesaria e inevitable para garantizar el sostenimiento del sistema representativo republicano.

\section{Los indígenas y la ciudadanía}

La concesión de la ciudadanía a los indígenas en la constitución de 1812 fue el resultado de un arduo debate en las Cortes que se inició a fines de 1810 y en el que se discutió si esta población tenía capacidad para ejercer su propia representación como el resto de los estamentos. El debate concluyó con la abrumadora derrota de los que plantearon su exclusión por considerarles en una permanente e irreversible minusvalía legal. El artículo quinto de la Constitución les incluyó en la amplia definición de la nacionalidad española que consideraba como tal a todos los hombres nacidos y avecindados en los territorios europeos y americanos pertenecientes a la Corona de España. Como ciudadanos con derecho a voto los indígenas intervinieron por primera vez en la elección de los miembros de los ayuntamientos constitucionales y de las diputaciones provinciales y, también, de los representantes ante las Cortes ordinarias celebradas entre 1812 y 1814. Los escasos estudios hasta la fecha realizados han resaltado que esta inédita participación en la esfera pública regional de los indígenas fue antes corporativa que individual como resultado de la persistencia de la antigua tradición pactista, su resistencia a perder la identidad comunitaria y la negativa de criollos y mestizos a ser gobernados por un alcalde o regidor indio (Demèlas, 2003, pp. 180-183). Pero también es fundamental reconocer que, fuera de las principales capitales de provincia, se instalaron algunos ayuntamientos constitucionales en los que se eligieron una mayoría de regidores indios, declinando tan solo la alcaldía en una persona letrada, tras una previa negociación y acuerdo con los sectores no indios (Núñez, 2005). Los indígenas volvieron a participar en las elecciones de los ayuntamientos y diputaciones provinciales durante la época del Trienio Liberal pero exclusivamente en las provincias del sur andino que se mantuvieron fieles al régimen constitucional español y al gobierno de La Serna establecido en el Cusco. La ausencia de estudios locales ha permitido afirmar a Nuria Sala i Vila que los indios tuvieron un escaso o nulo protagonismo en la conformación de los ayuntamientos capitalinos de Cusco, Arequipa y Huamanga (Sala i Vila, 2011, p. 695).

En el Estatuto Provisorio de 1821 sancionado por el Protectorado del general José de San Martín el reconocimiento de la independencia de España fue señalado como la única condición 
para adquirir la ciudadanía peruana. La impronta gaditana reapareció en las discusiones del congreso constituyente establecido 1822. En el discurso preliminar presentado por la comisión encargada de la redacción de la constitución en mayo de 1823 se justificó el mantenimiento del sistema indirecto de elección, aunque ya no de tres grados sino de dos grados, de los representantes a los poderes ejecutivo y legislativo como un mal necesario frente a la elección directa que era «la única que puede llamarse esencialmente libre» (Pons Muzzo y Tauro, 1975, p. 308-309). Los congresistas consideraron que la mayor parte de la población debido al atraso experimentado durante la dominación española no tenía una cultura política apta para decidir por sí misma a sus representantes. De ese modo también se justificó el voto de los analfabetos, cuya gran mayoría lo conformaban los indígenas quechuas y aymaras, por ser un derecho fundamental de los hombres que no se podía proscribir. La constitución en su artículo $17^{\circ}$ especificó que para ser ciudadano se requería ser peruano, casado o mayor de veinticinco años, tener una propiedad o ejercer un oficio sin sujeción a otro en clase de sirviente y, por último, saber leer y escribir «cuya calidad no se exigirá hasta después del año de 1840». Con esta decisión, en adelante, el destino del electorado indígena quedó supeditado al mantenimiento de una forma de elección universal, indirecta en dos grados y amplia al permitirse el voto de los analfabetos. Paradójicamente, también la condición de tributario, una exacción de la época colonial restablecida por Simón Bolívar en 1826, favoreció a los indígenas para acceder a la representación en calidad de contribuyentes. El caso peruano en el siglo XIX se distanció de lo ocurrido con la mayoritaria población indígena en otras realidades latinoamericanas, ya que, por ejemplo, en Ecuador los indígenas analfabetos fueron excluidos de la ciudadanía sin contemplaciones políticas en 1830 (Maiguashca, 1996, pp. 88-89). En Bolivia los analfabetos indígenas votaron hasta 1839. Ese año la constitución les excluyó, aunque Marta Irurozqui ha demostrado que mientras un sector indígena optó por transgredir ese precepto, otro sector acató resignadamente el requisito de aprender a leer y escribir como medio de participar en las elecciones censitarias (Irurozqui Victoriano, 2000).

La defensa del principio del voto indígena la sostuvo en todo momento la primera generación de políticos liberales. Ella dominó el congreso constituyente de 1823 y, pocos años después, la asamblea encargada de redactar la constitución de 1828. Esta última carta política confirmó lo dispuesto en 1823 con relación al derecho de los indígenas analfabetos a elegir a las autoridades nacionales. No solo eso, la constitución de 1828 especificó en su artículo $13^{\circ}$ que el elector parroquial si bien debía saber leer y escribir, de ese requisito estaban exceptuados «por ahora los indígenas con arreglo a lo que prevenga la ley de elecciones». En cambio la exigencia ineludible de poseer una propiedad que rinda quinientos pesos líquidos al año excluyó a los indígenas de poder ser elegidos como diputados. En la tercera constitución sancionada por la Convención Nacional en 1834 se confirmó básicamente todo lo dispuesto por la constitución de 1828 en relación con el asunto del mercado electoral indígena. En cambio, ligeras modificaciones en esta materia se produjeron en la primera constitución conservadora sancionada en 1839, sobre todo, porque se advirtió que el Estado incumpliría su cometido de alfabetizar a los indígenas en 1840 tal como se había dispuesto en 1823. Por eso el artículo octavo de la constitución pospuso el requisito de saber leer para ejercer la ciudadanía a «los indígenas y mestizos, hasta el año de 1844, en las poblaciones donde no hubiere escuelas de instrucción primaria». Esta excepción apuntaba a favorecer a la mayor de las comunidades indígenas instaladas en la serranía peruana en donde nunca se había establecido algún centro de instrucción. La condición también exigida de «pagar alguna contribución» para ejercer la ciudadanía complementó la participación de los indígenas tributarios como votantes y electores parroquiales.

Ni los indígenas, en su mayor parte por desconocimiento, celebraron su inclusión como electores en las elecciones nacionales ni tampoco los políticos más conservadores se mostraron 
conformes con esta participación que consideraban que el voto indígena era fácilmente manipulable. Uno de estos personajes, el sacerdote de un conservadurismo ultramontano Bartolomé Herrera, en el Congreso de 1849 se manifestó abiertamente contra la iniciativa de un grupo de diputados liberales liderados por Pedro Gálvez de prorrogar el voto de los indígenas analfabetos hasta 1860. Herrera sostuvo que los analfabetos carecían de la «soberanía de la inteligencia» que permitía solo a algunos el privilegio de poder redactar e impartir leyes conforme a un pacto social amparado por la ley divina. Proseguir con el derecho a elegir de los analfabetos significaba ir contra ese ordenamiento natural y jurídico y les perjudicaba porque les convertía en instrumentos de otros personajes que se beneficiaban con su voto. Gálvez replicó a Herrera que el derecho a voto era una derecho fundamental inalienable e imprescriptible, y que defender la capacidad de la inteligencia como principio de la ciudadanía era un requisito tiránico, opresor y propio del Antiguo Régimen. El debate concluyó con la aprobación de la enmienda constitucional de los liberales y prorrogó el voto de los analfabetos indígenas y mestizos hasta 1860 (Chiaramonti, 2005).

La Convención Nacional de 1855, dominada por la segunda generación republicana de políticos liberales, promulgó la quinta constitución en la que se estableció como novedad una ruptura radical con lo legalmente dispuesto desde 1812, es decir, la introducción de la elección directa del presidente y de los miembros del Congreso. El artículo $37^{\circ}$ estableció que este sufragio popular y directo «lo ejercen los ciudadanos que saben leer y escribir, o son jefes de taller, o tienen una propiedad raíz, o se han retirado después de haber servido en el Ejército o la Armada». Cabe advertir que tan solo dos años antes el general Ramón Castilla había abolido el tributo indígena por considerarlo un símbolo de oprobio heredado de la época colonial. ¿Qué supuso esta situación para los votantes indígenas? El presidente Castilla acató la constitución de 1856 pero no estuvo dispuesto a cumplir algunos de sus preceptos con los que no estaba de acuerdo, entre los que estaba suprimir el voto de los indígenas analfabetos. Por eso a través del fiscal de la nación José Simeón Tejeda aprobó en 1859 una resolución que permitió a esta población rural votar por cumplir el requisito de tener una propiedad raíz ya que «la ley del 31 de marzo de 1828 había reconocido sin lugar a dudas a los indígenas como propietarios de sus tierras; el hecho de que no se hubiese aplicado no invalidaba la ley» (Chiaramonti, 2005, p. 338).

La sexta constitución sancionada en 1860 por el propio general Castilla reintrodujo el sistema indirecto de la elección de los representantes nacionales. Asimismo, mantuvo el principio de que todos los analfabetos indígenas y mestizos tenían el derecho de votar porque el artículo $38^{\circ}$ permitía sufragar a aquellos que, sin cumplir el requisito de saber leer y escribir, en cambio fueran jefes de taller, tuvieran una propiedad raíz o pagaran al Tesoro Público una contribución. El reglamento electoral de 1861 fue más allá y garantizó la participación indígena en las elecciones parroquiales con representantes propios. Pero la ola electoral restrictiva que se propagó por varios países de América Latina en esas décadas llegó al Perú e impactó en un numeroso grupo de políticos descontentos con la forma en que hasta entonces se producían las elecciones. El nuevo discurso sobre la «verdad» electoral se sustentó en que la amplitud del voto concedida por la constitución de 1860 daba pie a las numerosas irregularidades que se cometían (violencia extrema en las campañas electorales y en la toma de las mesas electorales, manipulación y recrudecimiento de las duplicidades en los cómputos provinciales y calificación final arbitraria por parte del parlamento de tales resultados en beneficio del partido mayoritario). La solución esgrimida por este sector renovador fue acabar con esa impronta electoral heredada de 1812 e introducir el voto directo así como la restricción del sufragio a las personas alfabetas. En 1895 el presidente Nicolás de Piérola tras derrocar mediante una revolución al general Andrés Avelino Cáceres aprobó la reforma de artículo 38 de la constitución de 1860 que restringió el sufragio exclusivamente a los varones que tuviesen propiedades inmuebles de alto valor y supiesen leer y escribir. Tal como 
previeron los defensores del voto restrictivo, los indígenas analfabetos no se rebelaron contra esta medida que les marginó del mercado electoral por más de ochenta años. Estos volvieron a recobrar el derecho a votar recién en 1980.

\section{Los ayuntamientos constitucionales}

En el capítulo primero del título sexto de la constitución de 1812 quedó sancionado el funcionamiento de los ayuntamientos constitucionales como gobierno interior de los pueblos, los mismos que se ordenó lo integraran por elección popular indirecta anual de dos grados (reunión de juntas de vecinos y reunión de electores parroquiales) el alcalde o alcaldes, los regidores y el síndico procurador. Se especificó que en la nueva elección la totalidad de alcaldes fuesen renovados, mientras que los regidores y síndicos procuradores debían cambiarse por mitad. Otro artículo especificaba que el ciudadano que hubiese ejercido cualquier cargo capitular no podía ser inmediatamente reelecto pero si postular al segundo año. Para ser capitular se requería ser ciudadano en ejercicio de sus derechos, tener más de veinticinco años y demostrar cinco años de vecindad en el pueblo donde fuese elegido. Los empleos municipales eran una carga concejil y, por tanto, irrenunciables. La carta política señalaba que ningún empleado público nombrado por el rey, a excepción de los que sirven en las milicias nacionales, podía ser electo alcalde, regidor o síndico procurador. Entre las facultades de gobierno de los ayuntamientos resumidas en el artículo $321^{\circ}$ estaban las de controlar la policía de salubridad, administrar e invertir los caudales de propios y arbitrios, repartir y recaudar las contribuciones, cuidar de las escuelas de primeras letras, hospicios, casas de expósitos, construir y reparar los caminos, formar las ordenanzas municipales y, por último, promover la agricultura, industria y comercio. Por último, se ordenaba la creación de ayuntamientos en los pueblos de más de mil habitantes y se especificaba que todos estos organismos locales estaban sujetos a la supervisión de la Diputación Provincial.

La elección de los ayuntamientos constitucionales entre 1812 y 1814 fue el principal motor del cambio experimentado por la cultura política peruana hacia el sistema representativo (Peralta Ruiz, 2010, pp. 239-270). En las capitales de Lima y Cusco los críticos de las autoridades peninsulares se asumieron como defensores del constitucionalismo y emprendieron campañas electorales para controlar los ayuntamientos. Su triunfo en las elecciones parroquiales les garantizó la lucha contra las autoridades que ellos personificaban con el despotismo. Entre 1813 y 1814 el ayuntamiento constitucional de Lima estuvo enfrentado al virrey, mientras que el ayuntamiento del Cusco mantuvo un permanente conflicto con la Audiencia. En los ayuntamientos de menor calado el deseo de los actores políticos de procurar acomodar los resultados a sus intereses individuales y corporativos explican las irregularidades electorales. En muchos casos estas anomalías pudieron resolverse apelando a las negociaciones que entablaron los actores políticos en los momentos previos a la convocatoria de las elecciones parroquiales. Los pactos entre los ciudadanos indígenas y criollos fueron fundamentales en los poblados rurales, mientras que el acuerdo entre criollos y españoles fue clave en las capitales de provincia.

El restablecimiento de la constitución gaditana en 1820 en el Perú permitió que en algunos ayuntamientos, como el caso de Lima, se volviera a elegir por votación popular a los representantes. Pero el irreversible camino hacia la independencia sellado en la capital el 28 de julio de 1821 , limitó exclusivamente a las provincias realistas del sur andino la formación de los ayuntamientos constitucionales tal como se dispuso en 1812. Por su parte, el Protectorado establecido por San Martín y con influencia sobre las provincias independizadas del norte se impuso respetar la actuación de los gobiernos locales y por eso sancionó su propio reglamento provisional en el que estableció el método de las elecciones municipales para diciembre de 1822. A pesar de que en los considerandos del reglamento lo que se pretendía era establecer un modo de elección 
más liberal «para que [la elección] se ejerza con la debida dignidad y sin los obstáculos que le oponía la Constitución de la Península en la mayor parte inaplicable al Perú» (Oviedo, 1861, I, p. 308), en la práctica se mantuvo como fórmula el principio gaditano de la elección indirecta y anual en dos grados, el mismo número de capitulares elegibles y la condición de vecindad de los ciudadanos. La única novedad fue referirse en adelante a los ayuntamientos de indígenas como «pueblos de peruanos», una fórmula interpretada contemporáneamente como una imposición semántica que pretendió nacionalizar a una población a la que en la época se consideraba como la más perjudicada por el «retraso civilizador» que supuso la colonización española (Remy, 1988).

La constitución de 1823 definió en el título décimo como poder municipal el régimen encargado de la policía de orden, instrucción primaria, beneficencia, seguridad, salubridad y ornato, muy similar a lo dispuesto en 1812. Además se ratificó la elección indirecta, parroquial y anual de la mitad de aquellas autoridades. Para mayor semejanza con lo ocurrido en la época de las Cortes, ordenó que los alcaldes y, ocasionalmente los regidores, actuasen provisionalmente como los jueces de paz de sus respectiva poblaciones. Debido al estado de guerra en que se hallaba la república con España y la concesión de poderes dictatoriales a Bolívar para esta carta no tuvo vigencia. La constitución de 1828 rebajó por primera vez drásticamente la categoría de las municipalidades a la de una mera «junta parroquial de vecinos» que tienen la dirección de sus intereses locales. Mientras que el artículo $141^{\circ}$ sometía todas sus decisiones a la aprobación de la Junta Departamental, el artículo $142^{\circ}$ les negaba cualquier carácter representativo, lo que implicaba que «no pueden en ningún caso tomar parte ni intervenir bajo ningún pretexto en los asuntos que versan sobre intereses nacionales y que corresponden a alguno de los tres poderes de la República». Se les arrebataba de ese modo su antigua capacidad para constituirse en cabildos abiertos y demandar justicia a las autoridades mayores. La ley reglamentaria de municipalidades de junio de 1828, además, especificó que si bien entre las atribuciones de las mismas estaba la de formar ordenanzas municipales, éstas debían ser remitidas al Congreso para su aprobación por medio de la junta departamental que las debía acompañar con un informe propio aprobatorio o no. En cambio se mantuvo a los alcaldes y regidores su condición de jueces de paz y su elección indirecta por los electores parroquiales.

El progresivo declive del poder de las instituciones municipales en los años veinte tuvo su momento más álgido en la década siguiente. En la constitución de 1834 se arrebató a las autoridades municipales la potestad de ejercer como jueces de primera instancia. El Congreso puso como condición ineludible para ser electo y ejercer como juez el estar formados en la abogacía. No afectó a la institución únicamente ese cambio cualitativo sino también su drástica disminución cuantitativa derivada de la guerra civil que envolvió al país y que explica que «en 1834, solo en las capitales de departamento y provincia pudieran elegirse municipalidades» (Chiaramonti, 2007, p. 167). Finalmente, la constitución conservadora de Huancayo de 1839 suprimió la municipalidad, sustituyéndola por una intendencia de policía en cada capital de departamento, debiendo asumir esa intendencia en las provincias y distritos, respectivamente, los subprefectos y gobernadores. Lo único que sobrevivió a esa purga fue el cargo de síndico procurador al disponerse que hubiese dos en cada capital de departamento y provincia y uno en cada parroquia. No obstante, a mediados de 1845 el congreso aprobó una ley que restableció las municipalidades al considerar, primero, que la constitución si bien no las contemplaba en realidad no las prohibía, segundo, que eran instituciones reconocidas por las naciones más adelantadas y, tercero, que eran necesarias para «atender a las exigencias de los pueblos y la administración de los ramos de propios y arbitrios en cada uno de ellos» (Planas, 1998, pp. 161-162). Así el gobierno las convirtió en meros entes recaudatorios de impuestos de policía e instrucción que se asignaron al sostenimiento del presupuesto nacional. 
Los liberales restablecieron constitucionalmente las municipalidades en 1856. El artículo $115^{\circ}$ les atribuyó más potestades que la de un ente recaudatorio al conferirles la administración, cuidado y fomento de los intereses locales y sus respectivos establecimientos, la formación de los registros cívicos y el censo de la población. También restableció la elección anual y directa por parte del vecindario de la mitad de sus integrantes y les otorgó cierta autonomía en el manejo de sus fondos. La complementaria ley orgánica de municipalidades sancionada el 29 de noviembre de 1856 «retomando en cierta medida el modelo gaditano, dictaminó que se establecerían municipalidades - compuestas de un número diverso de miembros, a tenor de la población- en todas las capitales de distrito y en las "poblaciones que, aunque no sean capitales de distrito, tengan más de mil habitantes”» (Chiaramonti, 2007, p. 172). Esta legislación creó un nuevo cargo municipal al disponer que hubiese un teniente alcalde electo anualmente y cuya misión, además de asistir a las juntas, sería reemplazar al alcalde en todos los casos de imposibilidad. Pero lo más significativo de esta ley fue otorgar al municipio, además de sus tradicionales funciones de ornato y policía, atribuciones inéditas como proponer la terna para elegir al gobernador del distrito, señalar los distritos donde deben establecerse jueces de paz, nombrar a los tesoreros y recaudadores de fondos, a los empleados municipales y a los maestros de instrucción primaria (Oviedo, 1861, II, pp. 411-414). El municipio como poder local logró un reconocimiento que ni siquiera tuvo en la época de las Cortes de Cádiz al permitírsele crear nuevas contribuciones, controlar las elecciones directas, dirigir el ramo de beneficencia y determinar la conscripción para el ejército y la marina. De ahí que el general Ramón Castilla mostrase, antes de que la ley orgánica se aprobara, su disconformidad con la misma a través de una enmienda enviada a la Convención Nacional el 3 de noviembre de 1856. La objeción fundamental del presidente se centró en que se había otorgado a las municipalidades atribuciones que invadían el fuero privativo del poder ejecutivo y que ello generaría una perniciosa confusión legal. Pero la Convención no tomó en cuenta esta observación y aprobó el reglamento tal como fue originalmente formulado.

Gabriella Chiaramonti ha comprobado que tras entrar en vigor el reglamento municipal de 1856 se constituyó por sufragio directo un total de 699 corporaciones en todo el país. Esta explosión de gobiernos locales fue un momento excepcional que no volvió a repetirse tras la decisión del presidente Castilla de promover una nueva asamblea constituyente que reemplazase la para él incómoda e impracticable constitución liberal de 1856. El resultado fue la formación de un congreso dominado por los políticos conservadores que promulgó en 1860 una nueva carta política en cuyo breve artículo $118^{\circ}$, sobre las municipalidades, apenas se decía que las habrá en los lugares que designe la ley, «la cual determinará sus funciones, responsabilidad, calidades y el modo de elegirlos». Confeccionada a partir del principio formulado por el presidente del Congreso, Bartolomé Herrera, de que las municipalidades no eran cuerpos representativos sino administrativos, se sancionó su ley orgánica el 9 de mayo de 1861. En la misma la institución experimentó una serie de limitaciones a su naturaleza y a las facultades concedidas seis años antes. En primer lugar, estas se redujeron en número (de 669 a 92 corporaciones según Chiaramonti) al reconocerse solo la elección indirecta en dos grados y bianual de alcaldes y regidores en las capitales de departamento y de provincia. En las capitales de algunos distritos se dispuso más bien la creación de agencias municipales, entidades menores y dependientes de los ayuntamientos capitalinos, y el nombramiento de un síndico procurador por cada pueblo. En segundo lugar, las municipalidades quedaron sometidas en varias de sus actuaciones a lo que decidieran las autoridades nombradas por el Estado. Por ejemplo, el artículo $23^{\circ}$ prohibió a sus miembros tratar de asuntos de competencia de los prefectos o subprefectos y tomar disposiciones relativas al ramo de beneficencia, alta policía y seguridad pública. El artículo $14^{\circ}$ señaló que los alcaldes y regidores responsables y abusos y faltas en sus funciones podían ser denunciados por cualquier 
ciudadano ante el juez de paz, quien podía suspenderlos para proceder a su enjuiciamiento. El artículo $27^{\circ}$ ordenó que las municipalidades no podían enajenar, empeñar o hipotecar las propiedades municipales sin previa autorización de la prefectura. El artículo $112^{\circ}$ dispuso que «todo impuesto municipal que se hubiese creado desde 1857 hasta la fecha de esta ley, con motivo del restablecimiento de las municipalidades, dejará de existir y no tendrá efecto alguno, a menos que haya sido autorizado o aprobado por el cuerpo legislativo» (Albertini y Fuentes, 1861, p. 157). En otros articulados tampoco se permitió a los municipios cobrar nuevos derechos, contratar empleados o promover empréstitos si no contaban con la previa autorización del gobierno. En suma, prácticamente la normativa reglamentaria de 1861 constriñó a las municipalidades a una actuación subordinada a los agentes mayores gubernamentales (figuras estas por lo demás adaptadas del modelo de administración centralista francés) de forma mucho más precisa que la ambigüedad legal que se arrastraba desde 1812.

La desvinculación definitiva con la concepción doceañista del municipio se produjo con la sanción por parte del congreso del reglamento de municipalidades del 7 de abril de 1873 . El presidente Manuel Pardo la promulgó y entre las novedades que contuvo destaca el inédito cambio de denominación de la corporación ya que en adelante los tres niveles de municipios hasta entonces conocidos pasaron a denominarse, respectivamente, concejos departamentales, provinciales y distritales. Los mismos se renovaban por mitad cada dos años mediante elección indirecta, aunque se añadía que «la calificación electoral y personal de los miembros nuevamente elegidos, se hará por la mitad que hubiese quedado» (Anchorena, 1873, p. 11). En la práctica esto último supuso una inédita intromisión en los resultados de la elección parroquial. La ley aumentó significativamente el número de representantes en los concejos departamentales y provinciales. Al Concejo Departamental de Lima se le señaló un número fijo de cien miembros, mientras «los demás concejos departamentales estaban integrados por un diputado elegido por cada concejo provincial y veinticinco miembros elegidos por mayoría de votos de los colegios electorales de las provincias del departamento» (Planas, 1998, p. 223). Los concejos provinciales elegían anualmente presidente, vicepresidentes, inspectores de rentas, contralor de gastos e inspector de instrucción primaria, todos ellos constituían la junta directiva. Solo los concejos distritales conservaron la antigua estructura de alcalde, regidores y síndicos procuradores. Seguidamente, se estableció una estricta jerarquía piramidal entre los tres niveles y se especificó que los reglamentos de los concejos departamentales obligaban a los provinciales y los reglamentos de estos hacían lo propio sobre los distritales. El estricto constreñimiento legal de los concejos a la administración de los ramos de ornato, instrucción, baja policía, fomento de obras públicas y cobro de arbitrios, definitivamente los alejó de cualquier actuación vinculada a la esfera de la política mayor tal como lo desearon los gobernantes a partir de la segunda mitad del siglo XIX.

\section{La protección estatal de la religión}

La defensa de la religión católica en las Cortes de Cádiz precedió a la redacción de la propia constitución. En el decreto de la libertad de imprenta sancionado el 10 de noviembre de 1810 se especificó que la libre expresión de las ideas y críticas se constreñía estrictamente a lo político. $\mathrm{Su}$ artículo sexto especificaba que «todos los escritos sobre materias de religión quedan sujetos a la previa censura de los ordinarios eclesiásticos». Ninguna autoridad o individuo en España y América cuestionó ese postulado y, más bien, se alabó la defensa de la religión como una forma de evitar el reinado del ateísmo en que había caído Francia tras el estallido de la revolución de 1789. Ese precepto quedó reforzado en la constitución de Cádiz al añadirse en su capítulo segundo que «la religión de la nación española será perpetuamente la católica, apostólica y romana por ser la única verdadera, y que ella se protegerá por leyes sabias y justas, quedando prohibido el ejercicio 
de cualquier otra». Como señaló José María Portillo el principio anterior fue el fundamento jurídico y teológico de una comunidad de nación que superpuso a la soberanía de los individuos y de los pueblos una soberanía corporativa y territorial fundada en la defensa de la religión católica (Portillo, 2000).

Ascensión Martínez Riaza describe el complicado segundo momento que se vivió en el virreinato con la llegada de Madrid de la orden de restablecimiento de la libertad política de imprenta durante la etapa del Trienio Liberal. Ella señala que el nuevo reglamento de imprenta aprobado en las Cortes el 22 de octubre de 1820 quizás no se llegó a aplicar porque la situación a partir de 1821 había cambiado ya que, en sus palabras, «a partir de ahora se simultanean la legislación peninsular, que sigue regulando con escasa fortuna a los pocos periódicos fidelistas, y la legislación patriota que arranca del decreto de libertad de imprenta del Protectorado de 13 de octubre de 1821» (Martínez Riaza, 1984, p. 152). Esta historiadora sostiene que es probable que fuese el reglamento de imprenta de 1810 y no el de 1820 el que se aplicara en Perú durante la época del Trienio Liberal. Dependiendo del espacio geográfico donde se aplicase uno u otro reglamento, lo único cierto es que en ambos casos hubo una coincidencia en proteger la religión de cualquier crítica. El reglamento español de 1820 en su artículo segundo mantuvo como en 1810 la censura eclesiástica sobre los escritos religiosos y precisó que esa restricción se ceñía a los «escritos que versen sobre Sagrada escritura y sobre los dogmas de nuestra santa religión» (Marcuello Benedicto, 1999, p. 69). Por su parte, el reglamento de imprenta del Protectorado señaló en su artículo segundo que «el que abusando de esta libertad, atacare en algún escrito los dogmas de la religión católica, los principios de la moral, la tranquilidad pública y el honor de un ciudadano, será castigado en proporción a la ofensa, previo el dictamen, sobre la existencia del delito de la Junta Conservadora de la libertad de imprenta» (Puente Candamo, 1974, I, 336). Para no ser menos, el reglamento de imprenta sancionado por el Congreso Constituyente el 12 de noviembre de 1823 especificó en el artículo noveno que «los impresos que conspiren directamente a trastornar, o destruir la religión de la república, o su constitución política, se calificarán con la nota de subversivos» (Pons Muzzo y Tauro, 1975, III, p. 208). Además cabe advertir que el reglamento de 1823 estuvo vigente hasta 1908 (Martínez Riaza, 1984, p. 161). Los ejemplos anteriores son la prueba irrefutable de la coincidencia en proteger por todos los medios la creencia católica tanto entre los liberales hispánicos como entre los liberales de la naciente república.

La protección estatal de la religión en las constituciones del siglo XIX fue una virtual copia del artículo incluido en la carta política gaditana arreglado a los principios del sistema representativo. Esto quiere decir que la protección estatal de la religión católica se hizo en un nivel similar a la adopción de los principios irrenunciables de la ciudadanía y de la nación republicana. De hecho aquella apareció siempre mencionada al lado de éstas. En 1823 la constitución confirmó en su octavo artículo que la religión de la república es la católica, apostólica y romana con exclusión del ejercicio de cualquier otra. Además en la misma se agregó que era un deber de la nación proteger constantemente el catolicismo «por todos los medios conformes al espíritu del evangelio» y, asimismo, «un deber de cualquier habitante del Estado respetarla inviolablemente». Como en los tiempos de las Cortes de Cádiz el reglamento de libertad de imprenta sancionado en 1823 por el congreso constituyente determinó la persecución por parte de la junta de censura de todo autor cuyo escrito infamara a la religión. Cabe señalar que esta reglamentación de libre expresión política estuvo vigente a lo largo del siglo XIX. La constitución de 1828 repitió sin variación alguna lo dispuesto cinco años antes, es decir, que la nación protege el catolicismo apostólico y romano y no permite otro culto. Lo mismo se mantuvo sin variación alguna en el título primero, «de la nación y su religión», de la constitución de 1834 y en el título segundo, «de la religión», 
de las cartas políticas de 1839, 1856 y 1860. Lo que aparenta ser una postura política intolerante en los máximos códigos legislativos no fue, sin embargo, tan dogmáticamente aplicada por los gobiernos en la práctica cotidiana.

En los debates que se suscitaron entre los congresistas en varias legislaturas constituyentes si bien no hubo postura alguna que planteara la completa secularización del Estado, si se manifestaron propuestas para que este fuese más tolerante con otros cultos. Desde el primer congreso constituyente un sector dominado por liberales radicales, siempre minoritario, abogó porque se permitiera la libertad privada del culto a otras religiones bajo el pretexto de que con la protección exclusiva y excluyente del catolicismo podría ahuyentarse la inmigración europea, especialmente la inglesa, que había adquirido desde la independencia un especial protagonismo en el control de la economía peruana. Todas las enmiendas redactadas por los políticos partidarios de la tolerancia religiosa fueron rechazadas en las legislaturas parlamentarias a lo largo del siglo XIX. Tan solo el congreso constituyente de 1856 se atrevió a tocar tímidamente algunos privilegios económicos de la Iglesia como la eliminación del diezmo o la lenta extinción de las capellanías y censos eclesiásticos. Otra compensación que obtuvieron los derrotados partidarios de la tolerancia fue que el Estado actuase a lo largo de la primera centuria republicana con cierta laxitud o permisividad ante la cotidiana presencia en el país de congregaciones religiosas anglicanas que publicitaban sus biblias o celebraban cultos privados (Armas Asín, 1998, pp. 4041). También, cabe añadir que aunque se mantuvo la censura de imprenta a los escritos religiosos, entre ellos a los considerados antirománicos, en la práctica ésta no se aplicó y a nadie condenó el Estado por incurrir en tales delitos. El caso que confirma este aserto fue el del sacerdote liberal Francisco de Paula González Vigil.

Entre 1848 y 1856 González Vigil publicó en dos partes y diez tomos la Defensa de la Autoridad de los Gobiernos contra las pretensiones de la curia romana. En esta extensa obra denunció la intromisión de la iglesia romana en el gobierno de la iglesia peruana. Más allá del tema de la tolerancia religiosa, del que era partidario, Vigil propuso que el Estado debía dejar de proteger la religión católica y, más bien, someter a la Iglesia a su patronazgo para que esta pudiera regenerarse de los efectos perniciosos promovidos por Roma. Vigil resumió sus radicales proposiciones contra las pretensiones del Vaticano en un compendio de su Defensa en el que se sustentó que la curia romana carecía de las «aptitudes que se necesitan para gobernar bien, o para hacer felices a los pueblos en la senda que ahora llevan. Los gobiernos que no sean absolutos, proclaman la libertad, el progreso, las reformas y las mejoras en lo intelectual y material. La curia romana nada de esto entiende y por el contrario, tenaz en su propósito y en el sistema de sus pretensiones, aborrece las reformas; su tema es que no se hagan innovaciones, proscribe la libertad que proclaman las naciones, llama fatídico al progreso...» (González Vigil, 1857, pp. 321-322). Por eso defendió la necesidad de fomentar iglesias nacionales supeditadas a la autoridad de los gobiernos representativos. Ni el Estado peruano reaccionó contra estas palabras ni la ley de imprenta fue aplicada en contra de Vigil. En cambio, si hubo una andanada de ataques escritos y verbales por parte de los miembros de la Iglesia contra la Defensa de Vigil. El más importante fue el escrito en tres tomos publicado en 1852 en Barcelona por el sacerdote franciscano Pedro Gual con el título de El equilibrio entre las dos potestades. Gual en su polémica respuesta defendió al papado y sus derechos universales porque pretender «entorpecer el ejercicio de su autoridad, fundir los poderes divinos en los humanos, sería trastornar el orden establecido por el Ser Supremo y retrogradar a los siglos del despotismo» (Gual, 1856, III, p. 457). Otros sacerdotes que calificaron de sacrílegas las propuestas de Vigil en el púlpito fueron el ya citado Bartolomé Herrera y el obispo de Arequipa José Sebastián de Goyeneche. Vigil fue excomulgado por el papa Pío IX en 1851, pero lejos de retractarse prosiguió su carrera en la política y destacó como 
congresista en la redacción de los artículos anticlericales que infructuosamente intentó incorporar a la constitución de 1856.

Solo a fines del siglo XIX se consolidó el debilitamiento irreversible de la fuerza discursiva del alto clero peruano contraria a la pérdida de su privilegio como única religión del Estado. Al creciente influjo de una prensa liberal cada vez más inclinada a la tolerancia se sumó un sector de políticos radicales, abanderados por Manuel González Prada, que denunciaron periodística y literariamente las corrupciones y exacciones de los curas sobre todo en los ámbitos rurales e indígenas. Paralelamente, las iglesias protestantes aumentaron cuantitativamente su influjo sobre la sociedad, ya que a los anglicanos se sumaron los adventistas y los metodistas. El arraigo de los mismos entre la numerosa población extranjera fue tal que fue convirtiendo en un principio anacrónico el artículo cuarto de la constitución de 1860. Los políticos de la llamada República Aristocrática surgida en 1895 progresivamente se sumaron a la corriente de la tolerancia, denominada en la época como libertad de conciencia. En agosto de 1913 el senador Severiano Bezada presentó el proyecto de reforma del polémico artículo de la intolerancia religiosa por el que se suprimía la frase «el Estado no permite el ejercicio público de otra religión» (Armas Asín, 1998). Pese a la movilización del arzobispo de Lima, los demás prelados nacionales y movimientos como la Unión Católica contra la llamada «ola anticatólica», el Congreso aprobó la reforma 11 de noviembre de 1915. Correspondió al presidente Manuel Pardo con la promulgación de dicha reforma constitucional poner fin a uno de los articulados de más larga impronta de la constitución de 1812.

\section{Conclusiones}

A través de un breve recorrido por la trayectoria en el siglo XIX que tuvieron tres de los preceptos más importantes sancionados en la Constitución de Cádiz, a saber el voto de los analfabetos indígenas, la elección indirecta de los ayuntamientos provinciales y distritales y la protección estatal de la religión católica, se ha podido determinar el motivo de sus vigencias y, asimismo, de sus respectivas supresiones. Cronológicamente la de impronta más prolongada fue la última de las nombradas. La religión católica fue un culto estatal aceptado de modo consensual por liberales y conservadores, quizás porque un significativo porcentaje de los congresistas de ambas corrientes fueron eclesiásticos. Lo que se ha advertido en este artículo al respecto es que tanto el limitado número de inmigrantes de otras confesiones residentes en Perú como el modesto clima anticlerical, con apenas una gran polémica acerca del papel del Papado a mediados del siglo XIX, fueron razones suficientes para que los gobiernos tardaran en aceptar la tolerancia religiosa. En 1915 la alianza entre la iglesia católica y el Estado republicano terminó porque los políticos, y hasta minoritarios sectores católicos, comprendieron que mantener tal precepto era ir contra la corriente universal moderna de la libertad de conciencia. Otro caso de anacronismo es el de la persistencia del carácter representativo del ayuntamiento constitucional al estilo dispuesto por la constitución de 1812. Los políticos republicanos hasta 1834 respetaron a esta institución como órgano de las demandas locales ante la debilidad o ausencia de las autoridades estatales. Es a partir de esa década que la corriente conservadora enfila contra el carácter político del ayuntamiento, y su clara asociación con los tumultuosos cabildos abiertos, al punto tal de hacerlo desaparecer del organigrama administrativo en 1839. Su rescate en 1856 por parte de los liberales fue tal que se convirtió a la institución edilicia en un órgano representativo paralelo al poder delegado a los prefectos y subprefectos. Ello condujo a los políticos conservadores a cambiar la constitución en 1860 para reconvertir a los ayuntamientos de órganos representativos a instancias meramente administrativas. Fue este el preámbulo de la ley municipal de 1873 que adaptó y subordinó definitivamente a los flamantes concejos departamentales, provinciales y distritales a 
la estructura centralista administrativa de estilo francés que se mantiene hasta la actualidad. Por último, la persistencia hasta la reforma electoral de 1896 del voto de los indígenas analfabetos fue el legado de 1812 más positivo asumido por los políticos republicanos principalmente de la vertiente liberal. El simple hecho de permitir que este porcentaje mayoritario de la nación fueran ciudadanos y eligieran indirectamente a sus representantes municipales, a los legisladores y al presidente de la república, fue un avance con respecto a los otros dos países andinos que les arrebataron tempranamente tal derecho. Se puede aducir que el voto de los indígenas analfabetos fue en gran parte manipulado y usado por los políticos de turno para beneficiarse de un derecho político que aquellos desconocían, pero fue peor el remedio de excluirles del mercado electoral hasta 1978. Pero historiográficamente se ha demostrado que las contiendas electorales que se celebraron después de 1896 no derivaron en la «verdad del voto» sino en una nueva modalidad de fraudes y violencias ahora bajo un sistema electoral directo y restringido.

\section{Bibliografía}

Albertini, L. E. y Fuentes, M. A. (1861). La Constitución y leyes orgánicas del Perú dadas por el Congreso de 1860 comparadas con la que sancionó la Convención Nacional de 1855. Lima: Imprenta de la Gaceta Judicial.

Alvarado Luna, P. A. (2014). En Lima se estrellaron siempre sus avanzados proyectos: El virrey Joaquín de la Pezuela frente a la independencia del Perú, 1816-1820. Tesis de Licenciatura. Lima: Pontificia Universidad Católica del Perú. Recuperado en 27 de febrero de 2017 de http://tesis.pucp.edu.pe/repositorio/handle/123456789/6200

Anchorena, J. D. (1873).Traducción al quechua de la ley orgánica de municipalidades en lo relativo a los concejos de distrito. Lima: Imprenta del Estado.

Armas Asín, F. (1998). Liberales, protestantes y masones. Modernidad y tolerancia religiosa. Perú, siglo XIX. Cusco: Centro Bartolomé de las Casas y Pontificia Universidad Católica del Perú.

Chiaramonti, G. (2005). A propósito del debate Herrera-Gálvez de 1849: breves reflexiones sobre el sufragio de los indios analfabetos. En Aljovín de Losada, C. y López, S. (eds.) Historia de las elecciones en el Perú. Estudios sobre el gobierno representativo (pp. 325-358). Lima: Instituto de Estudios Peruanos.

Chiaramonti, G. (2005). Ciudadanía y representación en el Perú (1808-1860). Los itinerarios de la soberanía. Lima: Universidad Nacional Mayor de San Marcos-ONPE-SEPS.

Chiaramonti, G. (2007). De marchas y contramarchas: apuntes sobre la institución municipal en el Perú (18121861). En Araucaria. Revista Iberoamericana de Filosofía, Política y Humanidades, (18):, 150-179.

Demèlas, M. D. (2003). La invención política. Bolivia, Ecuador y Perú en el siglo XIX. Lima: Instituto Francés de Estudios Andinos e Instituto de Estudios Peruanos.

Gamas Torruco, J., Santiago Juárez, M. y Gutiérrez Hernández, A. (2014). La constitución de Cádiz en México. México: Universidad Nacional Autónoma de México.

García Belaunde, D. (1992). Los inicios del constitucionalismo peruano (1821-1842). En Ayer. Revista de Historia Contemporánea, (8): 147-162.

González Vigil, F. de P. (1857). Compendio de la defensa de la autoridad de los obispos contra las pretensiones de la curia romana. Lima: Imprenta Libre por Juan Infantas.

Gual, P. (1856). El equilibrio entre las dos potestades, o sea los derechos de la iglesia vindicados contra los ataques del Dr. D. F. de P. G. Vigil... Barcelona: Imprenta de Pons.

Hampe Martínez, T. (2015). Sobre la Constitución de 1812: Las Cortes gaditanas y su impacto en el Perú. En Palomino Manchego, J. F. y Naveja Macías, J. J. (coords.). La Constitución de Cádiz de 1812 (A propósito de su bicentenario) (pp. 927-939). Lima: Universidad Inca Garcilaso de la Vega.

Irurozqui Victoriano, M. (2000). 'A Bala, Piedra y Palo’. La construcción de la ciudadanía política en Bolivia, 1826-1952. Sevilla: Diputación de Sevilla.

Landavazo, M. A. y Sánchez Andrés, A. (2014). La influencia de Cádiz en la América española: política, gobierno y constitucionalismo. En Revista de Historiografia, (20): 75-96. 
Maiguashca, J. (1996). The Electoral Reforms of 1861 inEcuador and the Rise of a New Political Order. En PosadaCarbó, E. (ed.). Elections Before Democracy. The History of Elections in Europe and Latin America, (pp. 87-115). Londres: Institute of Latin American Studies.

Marcuello Benedicto, J. M. La libertad de imprenta y su marco legal en la España liberal. En Ayer. Revista de Historia Contemporánea, (34): 65-91.

Martínez Riaza, A. (1984). Libertad de imprenta y periodismo político en el Perú, 1811-1824. En Revista de la Universidad Católica, (15-16): 149-178.

Núñez, F. (2005). La participación electoral indígena bajo la Constitución de Cádiz (1812-1814) (pp. 381-386). En Aljovín de Losada, C. y López, S. (eds.) Historia de las elecciones en el Perú. Estudios sobre el gobierno representativo. (pp. 381-386). Lima: Instituto de Estudios Peruanos.

Nuria Sala i Vila (2016). Derecho, poder y libertad' a propósito de las batallas por la autonomía jurisdiccional entre las Audiencias del Cusco y Charcas (1820-1825). En Revista de Indias, LXXVI (266): 51-82.

Oviedo, J. (ed.) (1861). Colección de leyes, decretos y órdenes publicadas en el Perú desde el año de 1821 hasta 31 de diciembre de 1859. Lima: Felipe Bailly Editor.

Peralta Ruiz, V. (2005). De absolutistas a constitucionales. Política y cultura en el gobierno del virrey Pezuela (Perú, 1816-1820). (pp. 179-196). En Rodríguez O., J. (ed.). Revolución, independencia y las Nuevas Naciones de América. (pp. 485-510). Madrid: Fundación Histórica MAPFRE Tavera.

Peralta Ruiz, V. (2008). El impacto de las Cortes de Cádiz en el Perú. Un balance historiográfico. En Revista de Indias LXVIII (242): 67-96.

Peralta Ruiz, V. (2010). La independencia y la cultura política peruana (1808-1821), Lima: Instituto de Estudios Peruanos y Fundación M. J. Bustamante de la Fuente.

Planas, P. (1998). La descentralización en el Perú republicano (1821-1998). Lima: Municipalidad Metropolitana de Lima.

Pons Muzzo, G. y Tauro, A. (eds.) (1975). Colección Documental de la Independencia del Perú. Primer Congreso Constituyente. Lima: Comisión Nacional del Sesquicentenario de la Independencia del Perú, XV (3).

Portillo, J. M. (2000) Revolución de nación. Orígenes de la cultura constitucional en España, 1780-1812. Madrid: Centro de Estudios Políticos y Constitucionales y Boletín Oficial del Estado.

Puente Candamo, J. A. (ed.) (1974). Colección Documental de la Independencia del Perú. Obra Gubernativa y Epistolario de San Martín. Lima: Comisión Nacional del Sesquicentenario de la Independencia del Perú, XIII(1).

Remy, M. I. (1988). La sociedad local al inicio de la república. Cusco 1824- 1850”. En Revista Andina,(12): $451-484$.

Rubio Correa, M. (2003). La constitucionalización de los derechos en el Perú del siglo XIX. Lima: Pontificia Universidad Católica del Perú.

Sala i Vila, N. (2011). El Trienio Liberal en el virreinato peruano: los ayuntamientos constitucionales de Arequipa, Cusco y Huamanga, 1820-1824. En Revista de Indias, LXXI (253): 693-728.

Sala i Vila, N. (2016). 'Derecho, poder y libertad' a propósito de las batallas por la autonomía jurisdiccional entre las Audiencias del Cusco y Charcas (1820-1825). En Revista de Indias, LXXVI (266): 51-82.

Serna de la Garza, J. M. (2017). Influencia de la Constitución de Cádiz en México. Recuperado en 20 de abril de 2017 de https://archivos.juridicas.unam.mx/www/bjv/libros/8/3525/21.pdf.

Presentado: 28 junio 2017

Aceptado: 2 febrero 2018

Publicado online: 27 febrero 2018 